\title{
Professor Dr. José Pinto Antunes - Novo Diretor da Faculdade de Direito.
}

Professor Dr. José Pinto Antunes, nôvo diretor desta Faculdade, nasceu em Lorena a 9 de março de 1906. Foram seus pais o Sr. João Batista de Azevedo Antunes e D. Firmina Pinto Antunes.

Após os cursos primário e ginasial, concluídos em sua terra natal, matriculou-se simultâneamente na Faculdade de Direito de São Francisco e na Faculdade de Filosofia, Ciências e Letras de São Paulo, agregada, na época, à Universidade de Louvain.

Graduou-se em Filosofia, Ciências e Letras em 1926 e, em 1928, laureado como primeiro aluno, com o "Prêmio Rodrigues Alves", bacharelou-se em Direito.

Ingressando, logo depois, na política, participou ardorosamente das lutas cívicas do Partido Democrático, assumindo a Secretaria Geral, na presidência do Prof. J. J. Cardoso de Melo Neto, após 1932.

Foi ainda um dos fundadores do Partido Constitucionalista, pelo qual, em 1934, é eleito deputado à Assembléia Constituinte de São Paulo.

Implantado o Estado Novo, em 1937, abandona a política e reinicia suas atividades culturais. Faz o curso de doutorado nesta Faculdade e o de Ciência Sociais e Politicas na Faculdade de Filosofia da mesma Universidade, onde foi aluno dos grandes economistas francêses François Ferroux, René Courtin e Pierre Fromont da Universidade de Paris.

Em 1941, conquista a cátedra de Direits Industrial e Legislação do Trabalho na hoje Faculdade de Direito da 
Universidade Federal de Minas Gerais. Nomeado, exerce a cátedra até 1956 .

Nesse ínterim, conquista também a Livre Docência de Direito Constitucional, na Faculdade Nacional de Direito da Universidade do Brasil, e concorre à cátedra da mesma matéria nesta Faculdade, classificando-se em segundo lugar, pela diferença de um décimo, com duas indicações para a cátedra.

Em Minas exerce a cadeira de Economia Política no curso de bacharelado, de 1945 a 1951, e foi titular da cátedra de Economia Social e Legislação do Trabalho no Curso de Doutorado, desde 1951.

Fundou em sua terra natal a Faculdade Salesiana de Filosofia, Ciências e Letras, onde é titular da cadeira de Psicologia Racional na Secção de Filosofia.

É membro correspondente do Instituto Histórico e Geográfico da Bahia, do Instituto da Ordem dos Advogados de Minas Gerais, do Instituto de Direito Social de São Paulo e de outros.

Professor José Pinto Antunes dedicou-se também, intensamente, à pesquisa do Direito, possuindo variada bibliografia. Com a tese $A$ Produção sob regime de Empresa, concorreu à cátedra de Economia Política, nesta Faculdade; obtendo o primeiro lugar, toma posse a 9 de agôsto de 1956. Integrando, desde então, a Congregação de Professôres, participa, a contar de 1963, do Conselho Técnico da Faculdade e do Conselho Universitário.

Conhecendo de perto os problemas administrativos desta Escola, exerce a vice-diretoria em princípios de 1969, no impedimento do então diretor, Prof. Dr. Alfredo Buzaid, que assume interinamente a Reitoria da Universidade.

Em novembro, o Magnífico Reitor interino ascende ao Ministério da Justiça, deixando aberta a diretoria da Faculdade de Direito, para a qual é o Prof. Pinto Antunes o escolhido, dentre a lista tríplice, depois de uma indicação unânime dos seus pares. 


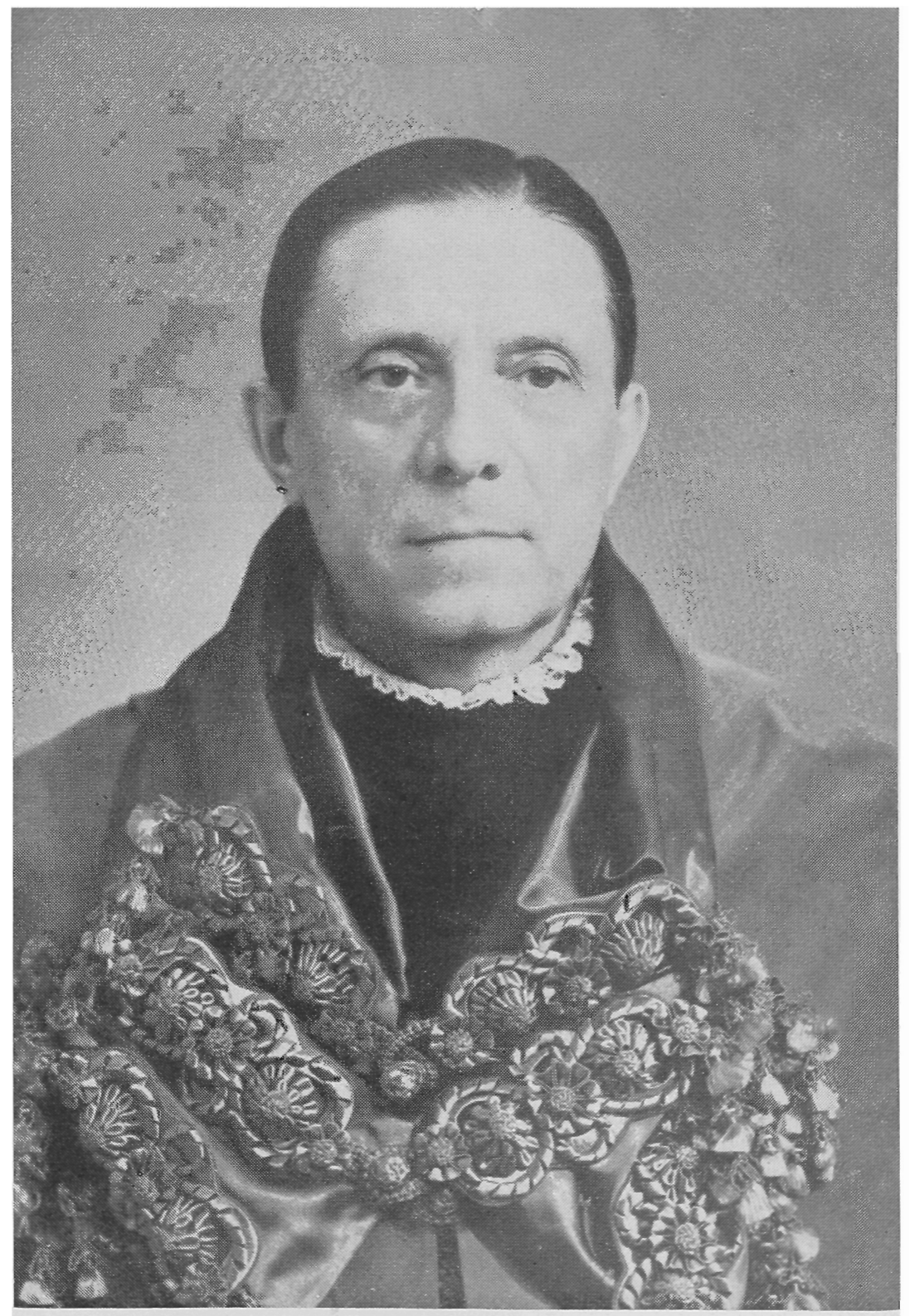

Nôvo diretor da Faculdade de Direito, Prof. Dr. José Pinto Antunes. 


\section{A solenidade de Posse.}

Em sessão solene da Congregação, realizada no salão nobre, a 17 de novembro, e presidida pelo Magnífico Reitor da USP, Prof. Miguel Reale, o novo diretor assume o cargo.

Aberta a sessão, foi introduzido no recinto pelos professôres Sílvio Rodrigues, Washington de Barros Monteiro e João Baptista de Oliveira e Costa Junior.

Além da Congregação e membros do Conselho Universitário, estiveram presentes altas personalidades entre as quais o representante do Exm..$^{\circ}$ Sr. Ministro da Justiça, Prof. Dr. Manoel Gonçalves Ferreira Filho, que transmitiu ao nôvo diretor a carta que se publica a seguir.

Carta do prof. Alfredo Buzaid, ministro da Justiça, ao novo diretor, prof. José Pinto Antunes.

São Paulo, 17 de novembro de 1969.

Excelentissimo Senhor Professor José Pinto Antunes, Dignissimo Diretor da Faculdade de Direito

Era minha intenção comparecer pessoalmente à solenidade em que Vossa Excelência é empossado no cargo de Diretor de nossa querida Faculdade.

Mas, circunstâncias imprevistas me impedem fazê-lo.

Em meu lugar, e como se fôsse eu, comparecerá o professor Manoel Gonçalves Ferreira Filho, que lhe transmitirá de viva voz os cumprimentos, com os melhores votos de uma feliz gestão.

Durante os meses em que exerceu a função de Diretor, o desempenho dêste cargo revelou as excepcionais qualidades de administrador, a que se aliaram o entranhado amor à Casa e o seu devotamento ao magistério.

Queira receber, com o cordial abraço, as saudações do amigo, colega e admirador

(ass.) ALFREDO BUZAID Ministro da Justiça 


\section{Discurso de saudação do Prof. Antonio Ferreira Cesarino Junior.}

Após a cerimônia de investidura no cargo, o novo diretor foi saudado, em nome da Congregação, pelo Sr. Prof. Dr. Antonio Ferreira Cesarino Junior que proferiu o seguinte discurso:

\section{I}

“A nossa presença nesta tribuna, neste momento, se explica por dois fatôres igualmente importantes: um sentimento de afeição e um imperativo de justiça.

\section{II}

Resulta o primeiro do fato de sermos colega do Prof. Pinto Antunes, na turma de 1928. Deu ela a esta Casa três catedráticos, o Prof. Basheu Garcia, o Prof. Pinto Antunes e o orador que vos fala e três livres docentes, o saudoso Prof. José Barbosa de Almeida, o Prof. Odilon de Araújo Grellet e o Prof. Caio Prado Junior.

Significa isto conhecermos o Prof. Pinto Antunes desde a nossa mocidade, distante apenas cronològicamente, pois não sentimos diminuídas as nossas energias, para a luta de cada um em prol de seus ideais. Pudemos, assim, acompanhar a sua esplêndida formação intelectual, não apenas como estudante do Curso de Bacharelado desta Faculdade, distinguido, como primeiro aluno da turma, com o "Prêmio Rodrigues Alves", mas também como participante do Curso de Doutorado e como aluno das Faculdades de Filosofia de São Bento e da Universidade de São Paulo, em que se diplomou em Filosofia e em Ciências Sociais e Políticas. 
Deputado estadual em 1937, foi o autor do projeto da lei n. 3.023, de 15 de julho dêsse ano, que ainda é o regulamento desta Faculdade, parcialmente em vigor. Nessa ocasião, dando demonstração de elevado descortino, criou nela a cadeira de "Legislação Social".

Em 1941 venceu brilhantemente, em Belo Horizonte, com o voto do Prof. San Tiago Dantas e o nosso, concurso para a cátedra de Direito Industrial e Legislação do Trabalho, que lecionou nos Cursos de Bacharelado e de Doutorado, da Faculdade de Direito, da Universidade de Minas Gerais. Mas não descansou: conquistou ainda, em eloqüentes provas, a livre docência de Direito Constitucional, na Faculdade Nacional de Direito, da Universidade do Brasil e nesta Escola.

Finalmente, em 1956, concorrendo com seis colegas de tão notável valor, que todos êles obtiveram a livre docência, se tornou professor catedrático de Economia Política desta Faculdade, em que tem lecionado desde aquela data, tanto no Curso de Bacharelado, como no de Especialização.

Voltou, assim, o Prof. Pinto Antunes à sua Escola, realizando, destarte, o que, em seu discurso de posse chamou de "... a minha ambição maior e suficiente ser Professor na Faculdade de Direito de São Paulo".

A sua bibliografia é grande e valiosa, por vários motivos. Não se satisfez sòmente com a compulsória elaboração de monografias para os numerosos concursos que prestou. Outros livros, tais como A Filosofia da Ordem Nova, Os Direitos do Homem no Regime Capitalista, Da Limitação dos Poderes e numerosos artigos e pareceres evidenciam a sua vasta cultura e a versatilidade do seu espirito.

\section{III}

O segundo motivo a que acima aludimos, é o fato resultante simplesmente do transcorrer do tempo - de 
sermos o decano da Congregação dos Professôres desta Faculdade. Pensamos, porisso, que os três decênios nela vividos intensamente nos qualificam para apreciar a maneira por que o Prof. José Pinto Antunes se houve como Vice-Diretor desta Faculdade, quando teve o ensejo de assumir-lhe a direção.

Em período tão curto, que a outros desanimaria, cuidou êle incansàvelmente do aperfeiçoamento desta Escola, tanío do ponto de vista de seu pessoal administrativo, como também de suas instalações.

Com uma coragem pouco encontradiça, que o levou a arrostar ameaças e inimizades, investiu contra abusos tão velhos que se haviam transformado em nociva rotina. Coin uma dedicação e um amor ao trabalho, que - se já mão conhecêssemos a sua "vontade teimosa" - seria de admirar no aristocrático quadrineto de Capitães-mores e mo descendente de velho estirpe portuguêsa que remonta a D. Sebastião, o nosso "Barão de Lorena" madrugou e madruga qüotidianamente nesta Faculdade, orientando-lhe constante e minuciosamente a remodelação dos serviços e o exato cumprimento de suas finalidades de ensino.

Mas, o que merece especial relêvo nesta conjuntura é a rara felicidade, o acertado tacto, com que tem sabido entender-se com o corpo discente da Faculdade, de molde a atender-lhe as reivindicações justas, sem quebra dos princípios da autoridade e da disciplina.

Não nos surpreendemos, portanto, de que, ao abrir-se a vaga de Diretor, fôsse o seu nome incluido na lista tríplice a ser enviada ao Govêrno do Estado, em votação secreta unânime dos membros da Congregação desta Faculdade. Patenteia isto que êle hoje assume em caráter efetivo a gestão dos destinos desta Escola, prestigiado pelo Magnífico Reitor, o várias vêzes premiado Prof. Miguel Reale, significativo expoente não apenas da Congregação dos Professôres desta Faculdade, mas também da cultura 
jurídica brasileira e internacional; prestigiado concordemente pela unanimidade de seus Professôres; prestigiado por seus estudantes; prestigiado pelos elementos sadios do seu corpo administrativo e, por último, prestigiado, inclusive, pelo orador dêste discurso, que é na Congregação dos Professôres, o líder da oposição, isto é, o líder de si mesmo...

\section{IV}

Não necessitamos, neste momento, dizer ao nosso novo dirigente o que dêle esperamos. $O$ seu passado como ViceDiretor é uma garantia de seu futuro como Diretor.

Cabe-nos, porém, saudando-o em nome do corpo docente, formular os melhores votos pelo êxito de sua administração.

$\mathrm{F}$, ao mesmo tempo, nos cabe o direito de ter certeza, de que, no seu exercício, êle não deixará de, honrando as gloriosas tradições de civismo desta Faculdade, pôr sempre em prática êstes magníficos princípios que enunciou em seu discurso de posse na cátedra de Economia Política: "Ensinei sempre os mesmos princípios - os da filosofia da dignidade do homem e as conseqüentes aplicações na ordem econômica e jurídica. A liberdade é o meu culto constante. Creio nela firmemente como fôrça criadora e até disciplinadora. A liberdade é o princípio de ordem na Economia e no Direito".

Disse."

Discurso de agradecimento do nôvo diretor.

Agradecendo a saudação recebida, o Prof. José Pinto Antunes proferiu seu "discurso de posse" nos têrmos seguintes : 
"Nunca antes me foi tão difícil usar da palavra como nesta circunstância e neste momento. Pressentia a dificuldade, até mesmo a impossibilidade da expressão verbal. Além da cortezia devida à dignidade da investidura, o escrever era antecipação das emoções, era a cautela que se impunha a um coração violentamente emocionado.

Vinha-me de longe êste estado d'alma. Os meus pares, meus queridos colegas, indicaram-me para Diretor desta Casa, pode-se dizer, pela unanimidade dos seus votos. No requinte da sua grandeza de espírito, Sua Magnificência, o Senhor Reitor, acolheu a indicação e, de pronto, fêz-me o que eu desejava ser, num sonho continuado de quase meio século, Diretor da Faculdade de Direito do Largo de São Francisco.

Pouco importa - a esta minha felicidade - o descompasso da sucessão; - venho logo depois de Alfredo Buzaid, o grande Mestre de Direito, reclamado pela Nação para repô-la nos quadros de uma nova estruturação democrática. Se não posso comparar-me a S. Excia., o Sr. Ministro da Justiça, no serviço, contento-me a igualar-me a todos, no amor que dedico a estas centenárias Arcadas.

Com Alcântara Machado, repito os hosanas do meu amor :

"e, incapaz de serví-la quanto devo, prezo-me de amá-la quanto posso."

Vem de longe, de muito longe, esta bem-querença. Vou contá-la. Perdoem-me êste passeio regressivo pelo passado, em que convoco, para alegrar comigo, pela saudade, a minha terra e a minha gente.

Quando começou, tudo dizia que se tratava de um amor impossivel.

Da "Gens Lorenensis", o "Azevedo" de meu Pai era do ramo de agricultores. Senhores da terra e amantes da terra, podiam dizer como Columella: 
... "apud antiquos nostros fuisse gloriae curam rusticationis".

Sim. Para os nossos antepassados foi motivo de glória cuidar das coisas rústicas.

$\mathrm{E}$ fomos todos embalados aos sons ritmados de um conselho que viera do velho Portugal, a terra dos meus avós :

"Semeia e cria e terás alegria".

Mas, já naquela época, pois o fenômeno não é nôvo, aquelas inscrições, assinalando os portais da nossa herdade, pareciam-nos conselho superado, e fazíamos mofa da experiência dos velhos, embora muitas vêzes secular.

O Poder político, que os outros ramos da família detiveram no Império, e, ainda, detinham na República, dementava o filho do agricultor.

E êle não resistiu... Virou as costas ao campo, fêz ouvidos moucos aos repetidos conselhos paternos e sonhou ser Bacharel e Bacharel em Direito pela São Francisco, pois na história pátria aprendera que, desde o ano de 1827, era na Academia de São Paulo que se escrevia, pelo feito de seus filhos, a História do Brasil.

Caipirinha de Lorena, com o diploma de Bacharel em Ciências e Letras, do Ginásio São Joaquim, em baixo do braço, entrei fácil no rigoroso vestibular e, como todos, que aqui ingressam, passei a falar, com orgulho, da minha Faculdade.

Amei-a o quanto pude, nos cinco anos de Bacharelado e quando me laurearam, com o "Prêmio Rodrigues Alves", acreditei que isto significava o consentimento do meu amor, pelos Mestres que a governavam.

Puro engano. Não queria deixá-la e bati-lhe à porta, por duas vêzes, pensando aqui ficar definitivamente. Da 
primeira, reprovaram-me e, na segunda, consentiram-me no amor à distância, permitindo-me uma livre docência.

Mas isto não me bastava. Era pouco para tão grande querer. Tinha tido uma infância feliz e não conhecia, até então, contrariedade aos meus desejos. Ressentido, indignado, passeei a minha revolta, ostentando vitórias em outras terras, como que dizendo, a modo de um capricho infantil, que outras Faculdades me queriam, quando a minha amada me recusava...

É difícil esquecer o primeiro amor e, também, não há quem vença uma vontade teimosa.

Retornei com ímpeto e, então, esta minha Escola não resistiu mais aos arrebatamentos do meu amor, dando-me uma de suas cátedras como preço, afinal, da provada eternidade do meu afeto:

"mais servira, se não fôra para tão longo amor tão curta a vida!"

E, hoje, digo-o com satisfação indizível e com gratidão sem medida, que cheguei ao término do meu longo pelejar, ao assumir, pelo favor dos meus colegas, o govêrno desta Casa.

Aquilo que vou fazer não é preciso dizê-lo. Completarei o que comecei e conservarei, aperfeiçoando, o que fiz nos poucos meses de interinidade da Diretoria, em substituição ao seu eminente Diretor efetivo, o Professor Alfredo Buzaid, agora Ministro da Justiça e que, hoje, nos honra com a representação de sua presença, a qual agradecemos penhoradamente.

Como Diretor, já estamos aplicando a reforma universitária de que esta Escola foi precursora. Pretendemos continuar, como no nosso passado secular, a formar juristas e estudiosos para atender, como sempre, aos reclamos da pátria comum. Também, com as modificações já intro- 
duzidas, durante a nossa interinidade, pretendemos ministrar, aos nossos futuros advogados, o conhecimento do seu tempo. Não queremos os diplomados de cultura marginalizada, pobres "chomeurs" intelectuais, sem profissão, ou melhor, profissionais da subversão, em busca de um mundo utópico onde haja lugar para os seus conhecimentos de coisa nenhuma.

Preparamos esta Casa, através dos variados Institutos, já em funcionamento, para formar profissionais que, defendendo a ordem econômica constitucional, fundada na livre iniciativa, saibam conter os excessos da concorrência que, dentro da licitude e lealdade, confunde-se com o próprio interêsse comum.

Não cremos na falada Universidade crítica pregada por aquêles pobres "chomeurs" de falsa cultura.

E aprendizagem, à moda da terra bandeirante, a que defendemos, na formação dos nossos bacharéis. O diploma, prova final de conhecimentos atualizados, deve propiciar a riqueza do profissional, condição material para o gôzo das liberdades individuais.

Repetimos, ainda, Alcântara Machado:

“o paulista é ávido dos bens materiais, porque tem horror à dependência."

E, acrescentaríamos, é também porque êle aspira sempre o Poder.

Quem quiser fazer voto de pobreza revolucionária, para viver de assaltos à propriedade privada que, entre nós, é direito individual, assegurado pela Constituição e pelas leis, não procure entrar pelas nossas portas, porque delas será expulso.

Dito isto, para conhecimento dos rumos da Direção que, hoje, solenemente, assumimos, voltemos ao nosso interrompido roteiro sentimental. 
Meus colegas, meus amigos:

Não sei o que dizer de vossa gentileza, quando para requinte da bondade, saúda-me, em nome de todos, com as palavras, que sei exageradas, porque brotadas de seu coração magnânimo, o eminente Mestre de todos nós, o Professor Antônio Ferreira Cesarino Jr., meu colega de turma, jurista consagrado, cujo nome é um serviço a esta Faculdade e ao Brasil pela sua gloriosa projeção internacional.

E a nomeação do Magnífico Reitor, quando o Reitor é Miguel Reale, já é glória demais para quem sonhava com muito, mas não lutava por tanto!

$O$ silêncio responde melhor que a palavra, pois esta vem do raciocínio e aquêle transborda do coração.

Agora, minhas Senhoras e meus Senhores, é tempo de ir embora e ao término das expressões de agradecimento, peço a todos uma carinhosa permissão ou tolerância para me recolher ao que me é mais intimo e profundo - a saudade doída e irredutível da casa e do terrunho em que nasci, onde passei tôda a minha infância e onde desejaria ficar, quando tiver que ficar para sempre.

Desculpem-me a ingenuidade da confissão daquilo que seria o meu último desejo.

Quando ainda me restassem lagumas fôrças para servir, queria ser eleito ou imposto, pouco se me dá o estilo da investidura, Prefeito da minha Cidade Natab a velha Hepacaré.

$\mathrm{E}$ vou contar o meu programa na minha última administração.

Queria restaurá-la na sua beleza imperial, que os iconoclastas da tradição vêm destruindo sem dó, nem piedade.

Reviveria os seus jardins gradeados, na geometria sentimental dos seus canteiros, os quais eram traçados em estrêlas de cinco pontas, trevo de quatro fôlhas e, ainda, 
até com o desenho daquela romântica lua nova, e, tudo, bem coberta de saudades, sempre-vivas de tôdas as cores, de perpétuas bem roxinhas, sem faltar as violetas perfumadas - tão acanhadas do seu perfume que era difícil achá-las entre as suas fôlhas presunçosas...

Queria, ainda, e queria muito, replantar as palmeiras imperiais da Rua Viscondessa de Castro Lima, que enfeitavam o caminho e se perfilavam solenes em homenagem àqueles que se mudavam, para sempre, para o lindo campo santo da minha terra natal, onde estão todos os mortos de que venho...!

Oh! Aquêles malvados, sem coração, que as deceparam até às raízes, não sabiam o quanto elas guardavam, em segrêdo de amor, para contar sòmente aos filhos da terra...

Em continência a um passado de três séculos, elas, erectas, imponentes, saudaram em sua passagem para o eterno repouso, as cinzas de dois Capitães-Móres que, servindo à Corôa, também serviram muito ao Brasil; 17 grandes do Império, notáveis homens da República e, até, os mortos sem acompanhamento elas saudavam, certamente, quando convocavam todos os sabiás, das jaboticabeiras e dos bambuais, para flautearem os seus cantos, a modo de carpideiras, dando para isso em paga o pouso seguro das suas frondes altas e imponentes copadas.

Minhas senhoras e meus senhores, acreditem, por favor, pois é verdade, muito verdadeira, que, em Lorena,

"as aves que aqui gorgeiam não gorgeiam como lá...

"Não permita Deus que eu morra Sem que eu volte para lá..." 